Article

\title{
Estimation of Aerodynamic Roughness Length over Oasis in the Heihe River Basin by Utilizing Remote Sensing and Ground Data
}

\author{
Qiting Chen ${ }^{1,2,3}$, Li Jia ${ }^{1,2, *}$, Ronald Hutjes ${ }^{4}$ and Massimo Menenti ${ }^{5}$
}

1 State Key Laboratory of Remote Sensing Science, Institute of Remote Sensing and Digital Earth, Chinese Academy of Sciences, Beijing 100101, China; E-Mail: chenqt@radi.ac.cn

2 Joint Center for Global Change Studies, Beijing 100875, China

3 University of Chinese Academy of Sciences, Beijing 100049, China

4 Earth System Sciences, Wageningen University, P.O. Box 47, Wageningen 6700 AA, The Netherlands; E-Mail: Ronald.hutjes@wur.nl

5 Department of Geosciences and Remote Sensing, Delft University of Technology, Stevinweg 1, Delft 2628 CN, The Netherlands; E-Mail: M.Menenti@tudelft.nl

* Author to whom correspondence should be addressed; E-Mail: jiali@radi.ac.cn; Tel./Fax: +86-10-6480-7982.

Academic Editors: Heiko Balzter and Prasad S. Thenkabail

Received: 20 November 2014 / Accepted: 23 March 2015 / Published: 27 March 2015

\begin{abstract}
Most land surface models require information on aerodynamic roughness length and its temporal and spatial variability. This research presents a practical approach for determining the aerodynamic roughness length at fine temporal and spatial resolution over the landscape by combining remote sensing and ground measurements. The basic framework of Raupach, with the bulk surface parameters redefined by Jasinski et al., has been applied to optical remote sensing data collected by the $\mathrm{HJ}-1 \mathrm{~A} / 1 \mathrm{~B}$ satellites. In addition, a method for estimating vegetation height was introduced to derive the aerodynamic roughness length, which is preferred by users over the height-normalized form. Finally, mapping different vegetation classes was validated taking advantage of the data-dense field experiments conducted in the Heihe Watershed Allied Telemetry Experimental Research (HiWATER) project. Overall, the roughness model performed well against the measurements collected at most HiWATER flux tower sites. However, deviations still occurred at some sites, which have been further analyzed.
\end{abstract}

Keywords: aerodynamic roughness length; remote sensing; regional scale; agricultural; Heihe 


\section{Introduction}

Aerodynamic roughness length $z 0 \mathrm{~m}$ is a surface parameter that scales the vertical profile of the horizontal component of wind speed and characterizes the ability of the surface to absorb momentum from airflow. In many applications of surface hydrology and meteorology, the aerodynamic roughness length is a very important parameter for estimating momentum, heat and mass exchange between the land surface and atmosphere [1].

The roughness length is the vertical length scale of the logarithmic wind profile, which is established when the air flow attains equilibrium (i.e., constant vertical momentum flux) with the underlying homogeneous surface under neutral conditions [2]. In field experiments, $z 0 \mathrm{~m}$ is usually directly estimated by fitting mean horizontal wind velocity observations at different levels with the logarithmic wind profile equation. Alternatively, $z 0 \mathrm{~m}$ is estimated from turbulence measurements by using the eddy covariance (EC) technique $[1,3,4]$. These methods can produce credible results when the underlying surface is relatively homogeneous. As a rule of thumb, the ratio of the effective fetch of the EC observations to the measurement height should be about 100/1 [5] so that the momentum flux is measured within the surface layer in dynamic equilibrium with the surface. The horizontal scale of variability of the land surface may lead to conditions where no constant (momentum) flux layer, i.e., no logarithmic wind profile, is established. Under such conditions the aerodynamic roughness length becomes an effective land surface property which requires complex measurements over large areas.

The aerodynamic roughness is closely related with the geometric features and distributions of the roughness elements [6]. Remote sensing data products can provide wide spatial coverage and efficient temporal sampling of vegetation canopies, making it possible to parameterize $z 0 \mathrm{~m}$ at the regional scale [7-12]. For instance, Sarwar and Bill (2007) used ASTER data to derive $z 0 \mathrm{~m}$ and, consequently, evapotranspiration over an irrigated area in the Indus Basin in Pakistan [12]. In a study conducted by Hasager and Jensen (1999) [8], $z \mathrm{~m}$ at high spatial resolution (30 m) was obtained from classified satellite images. In the past decades, several methods for estimating $z 0 \mathrm{~m}$ at the regional scale based on canopy structure features have been provided in the literature. For example, Brutsaert (1982) [2] noted that $z_{0 \mathrm{~m}}=0.13 \mathrm{~h}$ for a homogeneous vegetation canopy, where $h$ represents the height of the vegetation. Jia et al. (1999) used the Normalized Difference Vegetation Index (NDVI) to parameterize $z 0 \mathrm{~m}$ using an empirical relationship [13]. Lettau (1969) used the obstacle height and frontal area index to derive $z 0 \mathrm{~m}$ [14]. MacDonald et al. (1998) improved Lettau's method by considering the overlapping effects of obstacles at a high areal density of roughness elements [15]. Choudhury and Monteith (1988) derived $z 0 \mathrm{~m}$ by using the Leaf Area Index by applying the second order closure model of Shaw and Pereira (1982) [16,17]. Raupach (1992; hereafter referred to as R92) provided an approach for determining $z 0 \mathrm{~m} / \mathrm{h}$ based on a precise analysis of the drag partitioning, which he simplified in 1994 (hereafter referred to as R94) [18,19]. One common problem of these methods is that the parameters provided in the theoretical formulas are fixed, despite their dependence on vegetation type. Jasinski et al. (2005) revised the parameters in R92 by using the Method of Moments with four IGBP land cover classes: Grasslands, croplands, evergreen needleleaf forests, and open shrublands. These authors used data from several international field experiments and other published sources [20,21].

The canopy structure and $z 0 \mathrm{~m}$ of agricultural lands change rapidly during the growing season. Maps of time-dependent aerodynamic roughness length are useful to model land-atmosphere 
interactions. For example, Zhou et al. (2012) demonstrated that the agreement of simulated with measured sensible heat flux [22] was significantly improved by using a time-dependent $z 0 \mathrm{~m}$. The primary objective of this study is to develop and validate a method to determine time-dependent patterns of aerodynamic roughness at the regional scale using remote sensing data.

In this study, we used the R92 roughness model as a theoretical framework to estimate $z 0 \mathrm{~m} / \mathrm{h}$ in the middle reach of the Heihe River Basin in China. The parameters of the R92 model as revised by Jasinski et al. (2005) were adopted. In addition, we developed a method to estimate vegetation height so that the actual roughness length could be estimated from $z 0 \mathrm{~m} / h$.

In the following section, we describe the case study area, the HJ-1A/1B CCD remote sensing data, the ground observations, and the land cover map used to drive the revised R92 model. In Section 3, we further detail the theoretical framework, and in Section 4, we present the intermediate and final results, followed by a validation based on flux measurements at twelve towers sampling the major vegetation types in the middle reach of the Heihe River Basin. Finally, we discuss some of the weaknesses and merits of the approach, followed by some concluding remarks on this first-ever high-resolution time series of the aerodynamic roughness lengths during the growing season in the middle reach of the Heihe River Basin.

\section{Study Area and Data}

\subsection{Study Area}

The study area is located in the irrigated oasis in the middle reach of the Heihe River Basin around Zhangye, Gansu province, in the arid and semiarid region of northwest China. The Zhangye oasis is the main agricultural area in northwest China. Figure 1 is a 2012 land cover map of our study area. We produced this map by a supervised classification of multi-spectral data acquired by the HJ-1A/1B satellites. The training and evaluation samples were chosen from the available field survey data for the Zhangye oasis and high spatial resolution Google Earth images. The overall accuracy of the classification results reached $84.1 \%$, and the Kappa coefficient was 0.81 , which met the needs of this study.

The vegetation in the oasis is heavily dominated by crops (mainly spring corn, spring wheat, and vegetables, such as chili, celery, and cauliflower), with small areas of grasslands, wetlands (reed), and deciduous broad-leaved forests (Table 1). The oasis is surrounded by the Gobi desert (Figure 1) and has a continental dry climate [23]. The net radiation ( $\mathrm{Rn}$ ) can reach $800 \mathrm{w} / \mathrm{m}^{2}$ during the growing season. Under sufficient irrigation, the latent heat flux (LE) in July and August can exceed $70 \%$ of the Rn on the oasis. During the non-growing season, the sensible heat flux (Hs) becomes dominant. In the last 30 years, several large field experiments have been carried out in this region, including the Atmosphere-Land Surface Processes Experiment conducted in the Heihe River Basin (HEIFI) [24] between 1988 and 1992, the Watershed Allied Telemetry Experimental Research (WATER) [25] experiment conducted between 2007 and 2009 and the Heihe Watershed Allied Telemetry Experimental Research (HiWATER) [26] study conducted between 2010 and 2015. The ground data we used are from the last of these experiments. 


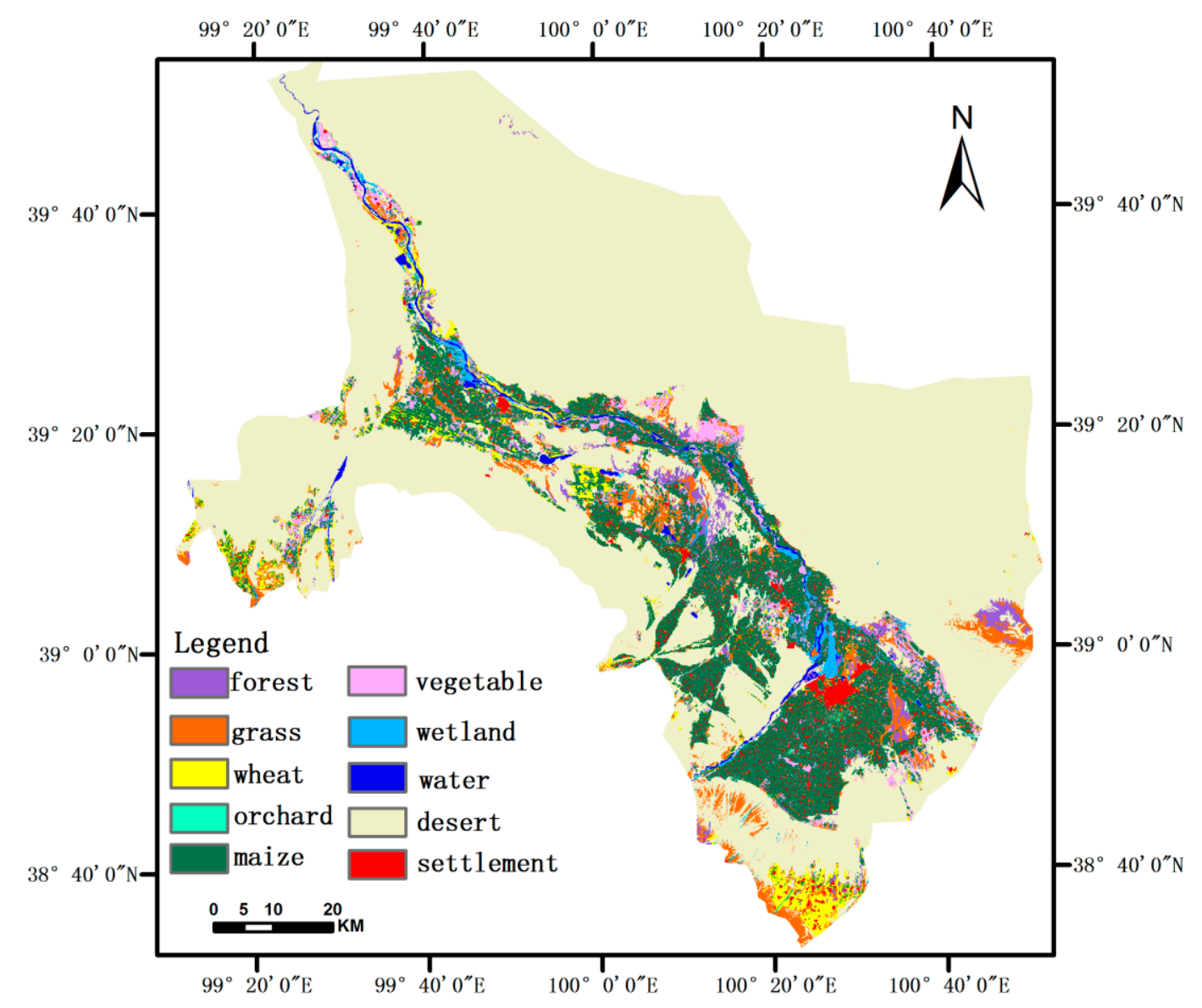

Figure 1. Land cover map of the middle reach of the Heihe River Basin in 2012.

Table 1. The fractional abundances of the main vegetation classes over the study area resulting from the classification in Figure 1.

\begin{tabular}{ccc}
\hline Vegetation Cover Class & Areal Percentage (\%) & Area $\mathbf{( k m}^{\mathbf{2}} \mathbf{)}$ \\
\hline Maize & 53.6 & 1294 \\
Wheat & 12.7 & 276 \\
Vegetables & 14.5 & 350 \\
Grassland & 11.5 & 308 \\
Forest & 4.5 & 109 \\
Orchard (apple tree) & 0.2 & 5 \\
Wetland & 2.9 & 71 \\
\hline
\end{tabular}

\subsection{Data}

\subsubsection{In Situ Data}

In this study, we collected growing season (May-September) EC data from field experiments at twelve sites. These relatively homogeneous sites included the main vegetation types in the middle reach of the Heihe River Basin, i.e., cropland, wetland, orchard, and forest vegetation, which represent a range of $z 0 \mathrm{~m}$ values from approximately $0.03 \mathrm{~m}$ to $0.8 \mathrm{~m}$. All EC observations (10 maize sites, 1 orchard site, and 1 wetland site) are products of the Multi-Scale Observation Experiment on Evapotranspiration over heterogeneous land surfaces that was conducted in 2012 (MUSOEXE-2012) [27,28] within the 
framework of HiWATER. For each EC site, an eddy covariance (EC) system and an automatic meteorological station (AWS) were installed, with a minimum of one 3-dimensional sonic anemometer, one $\mathrm{CO}_{2}$ and $\mathrm{H}_{2} \mathrm{O}$ gas analyzer, one four-component radiometer, one rain gauge, one wind speed sensor and one wind vane. The various EC and radiometer devices of the different models produced by different manufacturers used in the MUSOEXE-2012 were inter-compared in the Baji Gobi desert west of Zhangye City $\left(100^{\circ} 18^{\prime} 15.17^{\prime \prime}\right.$ E, 38 $\left.54^{\prime} 53.87^{\prime \prime} \mathrm{N}\right)$, and the inter-comparison campaign showed good agreement [27]. Table 2 contains the location information of all twelve EC sites.

Table 2. Information summary for the studied eddy covariance (EC) sites.

\begin{tabular}{cccccc}
\hline Site & Land Cover & \multicolumn{2}{c}{ Geographic Coordinates } & Obs. Height & Period (2012) \\
\hline EC01 & Maize & $100^{\circ} 21^{\prime} 54.83^{\prime \prime} \mathrm{E}$ & $38^{\circ} 52^{\prime} 36.37^{\prime \prime} \mathrm{N}$ & $3.8 \mathrm{~m}$ & $29 / 5-18 / 9$ \\
EC02 & Maize & $100^{\circ} 21^{\prime} 14.63^{\prime \prime} \mathrm{E}$ & $38^{\circ} 53^{\prime} 13.10^{\prime \prime} \mathrm{N}$ & $3.7 \mathrm{~m}$ & $7 / 6-19 / 9$ \\
EC03 & Maize & $100^{\circ} 21^{\prime} 2.34^{\prime \prime} \mathrm{E}$ & $38^{\circ} 52^{\prime} 32.78^{\prime \prime} \mathrm{N}$ & $3 \mathrm{~m}$ & $3 / 6-18 / 9$ \\
EC04 & Maize & $100^{\circ} 21^{\prime} 35.00^{\prime \prime} \mathrm{E}$ & $38^{\circ} 52^{\prime} 16.32^{\prime \prime} \mathrm{N}$ & $4.6 \mathrm{~m}$ & $28 / 5-21 / 9$ \\
EC05 & Maize & $100^{\circ} 22^{\prime} 35.28^{\prime \prime} \mathrm{E}$ & $38^{\circ} 52^{\prime} 21.17^{\prime \prime} \mathrm{N}$ & $3.2 \mathrm{~m}$ & $28 / 5-21 / 9$ \\
EC06 & Maize & $100^{\circ} 23^{\prime} 44.53^{\prime \prime} \mathrm{E}$ & $38^{\circ} 52^{\prime} 32.50^{\prime \prime} \mathrm{N}$ & $4.8 \mathrm{~m}$ & $4 / 6-17 / 9$ \\
EC07 & Maize & $100^{\circ} 20^{\prime} 31.12^{\prime \prime} \mathrm{E}$ & $38^{\circ} 52^{\prime} 11.77^{\prime \prime} \mathrm{N}$ & $3.5 \mathrm{~m}$ & $29 / 5-18 / 9$ \\
EC08 & Maize & $100^{\circ} 21^{\prime} 58.79^{\prime \prime} \mathrm{E}$ & $38^{\circ} 51^{\prime} 54.57^{\prime \prime} \mathrm{N}$ & $3.5 \mathrm{~m}$ & $28 / 5-21 / 9$ \\
EC09 & Maize & $100^{\circ} 21^{\prime} 11.23^{\prime \prime} \mathrm{E}$ & $38^{\circ} 51^{\prime} 31.27^{\prime \prime} \mathrm{N}$ & $4.6 \mathrm{~m}$ & $30 / 5-21 / 9$ \\
EC10 & Maize & $100^{\circ} 22^{\prime} 20.09^{\prime \prime} \mathrm{E}$ & $38^{\circ} 51^{\prime} 20.04^{\prime \prime} \mathrm{N}$ & $4.5 \mathrm{~m}$ & $25 / 5-15 / 9$ \\
EC11 & Orchard & $100^{\circ} 22^{\prime} 11.08^{\prime \prime} \mathrm{E}$ & $38^{\circ} 50^{\prime} 42.43^{\prime \prime} \mathrm{N}$ & $7 \mathrm{~m}$ & $31 / 5-17 / 9$ \\
EC12 & Wetland & $100^{\circ} 26^{\prime} 47.04^{\prime \prime} \mathrm{E}$ & $38^{\circ} 58^{\prime} 30.50^{\prime \prime} \mathrm{N}$ & $5.2 \mathrm{~m}$ & $25 / 6-26 / 9$ \\
\hline
\end{tabular}

The raw turbulence data were recorded at $10 \mathrm{~Hz}$ and averaged to $30 \mathrm{~min}$ intervals. Detailed information on data processing can be found in Liu et al. [28]. The following criteria were used for data selection: (1) $\mathrm{u}^{*}>0.15 \mathrm{~m} / \mathrm{s} ;$ (2) no rain; (3) $-1<(\mathrm{z}-\mathrm{d}) / \mathrm{L}<0.1$.

The leaf area index (LAI) and vegetation height $\mathrm{h}$ were manually measured at each site listed in Table 2 and one vegetable site $\left(100^{\circ} 21^{\prime} 29.26^{\prime \prime} \mathrm{E}, 38^{\circ} 53^{\prime} 35.59^{\prime \prime} \mathrm{N}\right)$ every few days during the growing season [29]. These measurements were used to estimate the empirical constants in Equations (7) and (8) (Section 3.2).

\subsubsection{Remote Sensing Data}

The HJ-1A/1B satellites were launched for environmental monitoring and disaster prevention by China on 6 September 2008 [30]. The data of the HJ-1A/1B satellites were obtained by combining the data acquired by the CCD (Charge Couple Device) sensors on both satellites (Table 3) resulting in a 2-day revisiting cycle with a $700 \mathrm{~km}$ swath from the visible to infrared wavelength spectrum.

Table 3. The main specifications of the HJ-1A/1B satellites and the Charge Couple Device (CCD) sensors.

\begin{tabular}{cccccc}
\hline Satellite Sensors & Band Number & Spectrum (mm) & Resolution (m) & Scene Width (km) & $\begin{array}{c}\text { Revisiting } \\
\text { Period (day) }\end{array}$ \\
\hline & 1 & $0.43-0.52$ & & \\
HJ-1A/1B CCDs & 2 & $0.52-0.60$ & 30 & 360 \\
& $3\left(\rho_{\text {red }}\right)$ & $0.63-0.69$ & & 4 \\
\hline
\end{tabular}




\section{Methodology}

\subsection{The R92 Remote Sensing Model to Estimate the Aerodynamic Roughness Length}

We used the method proposed by Raupach (1992) [18] (R92 model). The foundation of the R92 model [18] is a precise analysis of the drag partition between the roughness elements and the underlying substrate. A turbulent wake is generated downwind of individual roughness elements, and, with increasing density, drag will increase before they begin to shelter each other, stabilize and eventually decrease again. The R92 model rests on two hypotheses: (1) shelter area and volume are related to the structure of the roughness elements and (2) the bulk shelter effects of the individual elements can be superimposed randomly. The ratio of aerodynamic roughness length to canopy height, $z 0 \mathrm{~m} / h$, is expressed as follows:

$$
z_{\text {om }} / h=(1-d / h) \exp \left(-k \frac{u}{u^{*}}-\eta\right)
$$

where $k$ is the von Kármán constant (taken as 0.41$), z 0 \mathrm{~m}(\mathrm{~m})$ is aerodynamic roughness length, $h(\mathrm{~m})$ is the canopy height, $u_{\mathrm{h}}(\mathrm{m} / \mathrm{s})$ is the mean horizontal wind velocity at $h, u^{*}(\mathrm{~m} / \mathrm{s})$ is friction velocity, $d(\mathrm{~m})$ is the zero-plane displacement height, and $\eta$ is the profile influence function in R92, which accounts for the departure of the actual momentum diffusivity within the roughness sublayer from that above the roughness sublayer. In a study conducted by Raupach (1994), $z 0 \mathrm{~m} / h$ was insensitive to $\eta$. In this study, $\eta=0.193$ was used as in R94.

In Equation (1), the ratio $u \mathrm{~h} / u *$ is related to the bulk drag coefficient $(u * / u \mathrm{~h})^{2}$, which was approximated by using the following dimensional analysis:

$$
\begin{gathered}
\frac{u^{*}}{u_{h}}=\frac{1}{\gamma}=\left(c_{s}+c_{r} \lambda\right)^{1 / 2} / \exp (c \lambda \gamma / 2) \text { for } \lambda<\lambda_{\max } \\
\frac{u^{*}}{u_{h}}=\left(\frac{u^{*}}{u_{h}}\right)_{\max } \text { for } \lambda>\lambda_{\max }
\end{gathered}
$$

where $c_{\mathrm{s}}$ and $c_{\mathrm{r}}$ are the drag coefficients of the underlying substrate and an individual roughness element respectively, $c$ is a constant accounting for overlapping effects of elements, and $\lambda$ is the frontal area index, which is usually replaced by the canopy area index $(\Lambda)$. For isotropically oriented canopy elements, $\lambda$ and $\Lambda$ are simply related as $\lambda=\Lambda / 2$ [19]. Equation (3) implies that, the drag stress due to aerodynamic drag will remain constant when the areal density of roughness elements increases beyond a critical value.

In Equation (1), the ratio of the zero-plane displacement height to $h, d / h$, was deduced according to Thoms's center-of-pressure hypothesis, which defines $d$ as the vertical height of momentum absorption as [31]:

$$
\frac{d}{h}=\left(\frac{\beta \Lambda}{2+\beta \Lambda}\right)\left(1-\alpha \gamma^{-1} \Lambda^{-1 / 2}\right)
$$

where $\alpha$ is an empirical constant associated with the geometric structure of roughness elements, and $\beta$ is the ratio of $c_{\mathrm{r}}$ to $c_{\mathrm{s}}$. The substrate drag coefficient, $c_{\mathrm{s}}$, which is constant in agricultural areas, was assumed $=0.003$, as proposed in $\mathrm{R} 94$.

In this method, five roughness parameters, $\mathrm{c}_{\mathrm{r}}, \alpha, c,\left(u^{*} / u\right)_{\max }$ and $\Lambda_{\max }$, are crucial. Jasinski et al. [20] has applied the Method of Moments to estimate these five parameters for four IGBP land cover classes, evergreen needleleaf forests, grasslands, croplands, and open shrublands. In our study area, more 
vegetation types are found than the four Jasinski's classes. Following the method of Borak et al. (2005) [21], all vegetation types in our study area are associated with most similar ones of the four classes parameterized by Jasinski et al. (2005) [20]. The parameters for each vegetation class in our study are shown in Table 4.

Table 4. Parameters applied in the R92 model for the study area of Heihe River Basin for 2012 (adapted from [20,21]).

\begin{tabular}{cccccc}
\hline Vegetation Cover Class & $\boldsymbol{c}_{\mathrm{r}}$ & $(\boldsymbol{u} * / \boldsymbol{u})_{\max }$ & $\boldsymbol{c}$ & $\boldsymbol{\alpha}$ & $\boldsymbol{\Lambda}_{\max }$ \\
\hline $\begin{array}{c}\text { Forest } \\
\text { Orchard }\end{array}$ & 0.14 & 0.29 & 0.18 & 1.8 & 3.2 \\
\hline $\begin{array}{c}\text { Grass } \\
\text { Wetland }\end{array}$ & 0.23 & 0.32 & 0.28 & 1.53 & 2.3 \\
\hline $\begin{array}{c}\text { Maize } \\
\text { Wheat } \\
\text { Vegetables }\end{array}$ & 0.11 & 0.26 & 0.17 & 2.46 & 3.0 \\
\hline
\end{tabular}

\subsection{Canopy Structure Parameters}

\subsubsection{Canopy Area Index}

The canopy area index $\Lambda$ was used to express the canopy density, and composed of two parts: One-side area of all green canopy elements per unit ground area, i.e., the Leaf Area Index $L A I$, and the dead leaf and woody branches area, denoted as $L_{\mathrm{s}}$ :

$$
\Lambda=L A I+L_{s}
$$

$L_{\mathrm{s}}$ was computed using the method of Zeng et al. (2002) [32] as follows:

$$
L_{s}^{n}=\max \left\{\left[\beta L_{s}^{n-1}+\max \left(L A I^{n-1}-L A I^{n}, 0\right)\right], L_{s \min }\right\}
$$

where $L_{\mathrm{smin}}$ is the minimum $L_{\mathrm{s}}$, which consists of stems and dead leaves and depends on the vegetation type, $n$ denotes the $n$th month, and the term $(1-\beta)$ denotes the monthly removal rate of the dead leaves.

Satellite measurements of Red and NearInfraRed radiance can be used to determine the NDVI. Many studies, including early spectroradiometer measurements, documented a strong correlation between NDVI and ground measurements of LAI [33-35].

We used an empirical exponential relationship between $N D V I$ and $L A I$ to map $L A I$ :

$$
\operatorname{LAI}(\mathrm{x}, \mathrm{y}, \mathrm{t})=a \times N D V I^{b}(\mathrm{x}, \mathrm{y}, \mathrm{t})
$$

where $a$ and $b$ are empirical parameters that depend on vegetation type. Once the constants ( $a$ and $b$ ) for each vegetation type are known, $\operatorname{LAI}(x, y, t)$ can be mapped from $\operatorname{NDVI}(x, y, t)$, and the latter can be determined using the Red and NearInfraRed radiometric data acquired by the HJ-1A/1B satellites.

Field measurements of $L A I$ during the growing season at the $12 \mathrm{EC}$ sites and one vegetable site and the concurrent $30 \mathrm{~m}$ satellite $N D V I$ were used to estimate the constants ( $a$ and $b$ ) for each vegetation type by applying Equation (7) and minimizing the least squares residuals. For wheat, grassland and forest where the field $L A I$ measurements were not available, the empirical constants for Equation (7) were set to the same values as maize, reeds and orchard, respectively. 
Finally, 5-day time series of LAI maps between May and September 2012 were produced. First, 37 cloud-free images (approximately $50 \%$ of the available 75 overpasses) of HJ-1A/1B with $30 \mathrm{~m}$ spatial resolution were pre-processed using an image-to-image geometric correction, followed by radiometric and atmosphere corrections; then, the 37 NDVI maps of $30 \mathrm{~m}$ spatial resolution were used to reconstruct a gap-free NDVI time series from May to September of 2012 using the Harmonic ANalysis of Time Series (HANTS) approach, and then the time series of $L A I$ maps using Equation (7). The HANTS is a method for time series analysis and reconstruction based on the principles of Fourier Transform by decomposing a periodical series into Fourier components and it is a reliable method commonly used by many researchers for time series reconstruction [36]. HANTS has multiple advantages: It can deal with time series with irregularly spaced observations, detect outliers automatically, and capture the complex phenology of land cover by estimating the amplitude and phase of the periodic components used to model the NDVI time series [37,38]. Figure 2 shows an example of the original and reconstructed time series of NDVI using the HANTS approach.

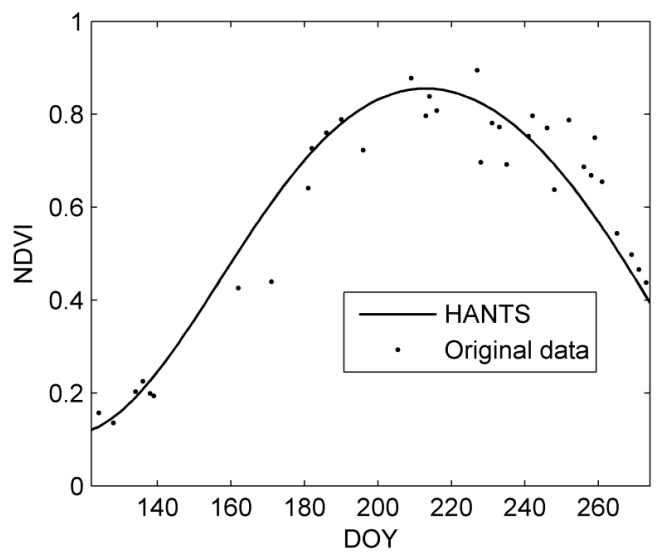

Figure 2. Observations (dots) and the HANTS reconstructed (solid line) NDVI time series for one pixel in oasis area of Heihe River Basin in 2012.

\subsubsection{Vegetation Height}

A map of vegetation canopy height is required to obtain a map of the aerodynamic roughness length parameter $z 0 \mathrm{~m}$ using the ratio $z 0 \mathrm{~m} / h$ estimated using Equation (1). Multi-spectral image data cannot be used to estimate directly canopy height. Satellite-based laser altimeters (i.e., the Geoscience Laser Altimeter System (GLAS) on Ice, Cloud, and land Elevation Satellite (ICEsat)-1/2 [39]) can provide measurements of vegetation height along the satellite ground-track, but the ICEsat across-track separation is about $60 \mathrm{~km}$ in the study area, so not sufficient for the purpose of this study. Airborne LiDAR with high spatial density detection could provide a higher resolution Digital Elevation Model (DEM) and Digital Surface Model (DSM) [40-42]. Vegetation height could be retrieved from the differences between the DSM and DEM values in the vegetated regions [7,9-11]. Airborne LiDAR data were acquired in the study area in 2012, and mapping $h$ and $z 0 \mathrm{~m}$ by utilizing the LiDAR data will be the subject of another study in the near future.

We mapped vegetation height, $h$, using an empirical relationship with $L A I$, constructed using ground measurements collected at most of the sites listed above (Table 2). The evolution of $h$ and $L A I$ is nearly simultaneous in herbaceous crops like maize [43], in which case $h / h_{\max }=L A I / L A I_{\max }$ at any time during 
the growing season, while in some species $h$ tracks $L A I$ and in other ones is the other way round. We used two empirical species-dependent parameters to account for this time-lag. The general form of our empirical relationship reads:

$$
\frac{h}{h_{\max }}(\mathrm{x}, \mathrm{y}, \mathrm{t})=\min \left(\mathrm{e} \frac{L A I}{L A I_{\max }}(\mathrm{x}, \mathrm{y}, \mathrm{t})+f, 1\right)
$$

where $e$ and $f$ are the empirical species-dependent parameters: (1) $e>1$ applies when the maximum vegetation height is reached earlier than the maximum $L A I$; (2) $e<1$ when the maximum vegetation height is reached later than the maximum $L A I$; and (3) $e=1$ and $f=0$ in Equation (8) give $h / h_{\max }=L A I / L A I_{\max }$.

The detailed steps for vegetation height estimate are:

1. Ground measurements of $h$ and $L A I$ for each annual herbaceous plant at the $11 \mathrm{EC}$ sites (10 maize sites and 1 wetland site) and one vegetable site were divided by the highest observed value of $h$ and $L A I$ at each site.

2. The normalized vegetation height $\left(h / h_{\max }\right)$ and leaf area index $\left(L A I / L A I_{\max }\right)$ values were used to estimate the constants $(e, f)$ by applying Equation (8) and minimizing the least squares residuals for maize, wetland, and vegetable.

3. For wheat and grasslands where no measurements of $h$ and $L A I$ were available, the empirical constants ( $e$ and $f$ ) in Equation (8) were set equal to those of maize and wetland vegetation, respectively.

4. Equation (8), the values of the $L A I_{\max }$ and $h_{\max }$ and the revised empirical constants $(e$ and $f$ ) were used to map vegetation height.

In Step 4, $L A I_{\max }$ was set to the maximum $L A I$ (retrieved using Equation (7)) for each pixel over all dates, the $h_{\max }$ values for maize, wetland and vegetable were $1.8 \mathrm{~m}, 1.6 \mathrm{~m}$ and $0.5 \mathrm{~m}$ respectively, based on the field measurements, and the $h_{\max }$ values for wheat and grass were $1.0 \mathrm{~m}$ and $0.5 \mathrm{~m}$, respectively, which is in agreement with past experiences. Furthermore, the vegetation heights of the orchard and forest were considered constant and were $5 \mathrm{~m}$ and $8 \mathrm{~m}$, respectively, during the whole growing season based on local experience.

\subsection{Local Roughness Lengths Estimated from Eddy-Covariance Measurements}

The aerodynamic roughness length was estimated from the eddy covariance measurements at the sites listed in Table 2 to evaluate the map of aerodynamic roughness length constructed using Equation (1). In the boundary layer the Monin-Obukhov similarity theory applies and the scaled profile of the mean horizontal wind speed reads:

$$
u(z)=\frac{u^{*}}{k}\left[\ln \left(\frac{z-d}{z_{\text {om }}}\right)-\psi_{m}\left(\frac{z-d}{L}\right)\right]
$$

which can be expressed as:

$$
\ln \frac{z-d}{z_{\text {om }}}=\frac{k u(\mathrm{z})}{u^{*}}+\psi_{m}\left(\frac{z-d}{L}\right)
$$

Here, $L$ is the Monin-Obukhov length, $\psi \mathrm{m}$ is the stability correction term and the displacement height $d$ cannot be accurately derived from eddy covariance measurements. For dense and uniform vegetation the simple relationship $d=2 / 3 \mathrm{~h}$ applies [6] and was used in this study.

Chen and Wang (1993) found that the value of $k u(z) / u^{*}+\psi_{\mathrm{m}}$ depends on stability, becoming higher under stable conditions and lower under unstable conditions. By plotting $k u(z) / u^{*}$ against $(z-d) / L$ for 
both stable and unstable conditions, the two intercepts of the fitted lines, i.e., at $\psi_{\mathrm{m}}=0$ (neutral conditions), provide $\ln ((z-d) / z 0 \mathrm{~m})$, which gives estimates $z 0 \mathrm{~m}$ values applying to the height of the EC measurements [44]. Our calculation of $z 0 \mathrm{~m}$ was done by applying this method. In this study, half hourly data were filtered based on criteria defined in Section 2.2.1. The filtered $u(z), u^{*}$ and $L$ measurements for each 5 days period, during which we assumed that the aerodynamic roughness was constant, were divided into two groups: Stable and unstable conditions. Then, a robust regression method (MatLab@ routine "robustfit"), which can minimize the influences of outliers, was used to perform a linear fitting between $(z-d) / L$ and $k u(z) / u^{*}$ for stable and unstable data to obtain the intercepts. Finally, the degrees of freedom for unstable and stable data fittings were used as weighting factors to obtain the weighted intercept and the mean value of $z 0 \mathrm{~m}$ over 5 days. In addition, the standard error of the regression coefficient estimates was used to indicate the uncertainty of the observed $z 0 \mathrm{~m}$.

\section{Results}

\subsection{Canopy Structure Parameters Estimated from Remote Sensing Data}

The coefficients ( $a$ and $b$ ) in Equation (7) for different vegetation types were obtained by least squares regression analysis using filed $L A I$ measurements collected at the $12 \mathrm{EC}$ sites and one vegetable site, and HJ-1A/1B NDVI data for the pixel of the corresponding site. The results together with the correlation coefficient (R) and the root mean square error (RMSE) are shown in Table 5. Due to lack of field LAI measurements over forest, wheat and grass, the relationships for these three surfaces were chosen to be same as those of orchard, maize, and wetland, respectively. A summary of the NDVI-LAI relationships is shown in Table 5 .

Table 5. The empirical constants in the $N D V I$ and $L A I$ relations (Equation (7)) for different vegetation types used in this study.

\begin{tabular}{ccccc}
\hline Vegetation Type & $(\boldsymbol{a}, \boldsymbol{b})$ & $\mathbf{R}$ & RMSE & Number of Observations \\
\hline $\begin{array}{c}\text { Maize } \\
\text { Wheat }\end{array}$ & $(6.2784,2.3011)$ & 0.91 & 0.63 & 112 \\
\hline Vegetable & $(8.5609,4.1193)$ & 0.65 & 0.66 & 7 \\
\hline $\begin{array}{c}\text { Orchard } \\
\text { Forest }\end{array}$ & $(4.9578,2.1994)$ & 0.87 & 0.20 & 6 \\
\hline $\begin{array}{c}\text { Wetland } \\
\text { Grass }\end{array}$ & $(9.8268,3.4428)$ & 0.63 & 0.80 & 13 \\
\hline
\end{tabular}

The $L A I$ map was constructed using Equation (7) applying the empirical coefficients in Table 5 to the HJ-1A/1B NDVI data in combination with the land cover map. For each 5 days period, the map of the canopy area index $\Lambda$ was then produced by applying Equations (5) and (6) to the LAI map. Figure 3 depicts the evolution of the area-averaged $\Lambda(t)$ for each vegetation class listed in Table 1 . It is found the $\Lambda(t)$ first began to increase during the vegetative growth stage and decrease during senescence. All vegetation types exhibit clear seasonal variations in $\Lambda$. Cropland and wetland vegetation showed a more pronounced seasonality because of the relatively low dead-leaf removal rate. Differences in the phases of $\Lambda(t)$ among classes indicate differences in the phenology of vegetation. 


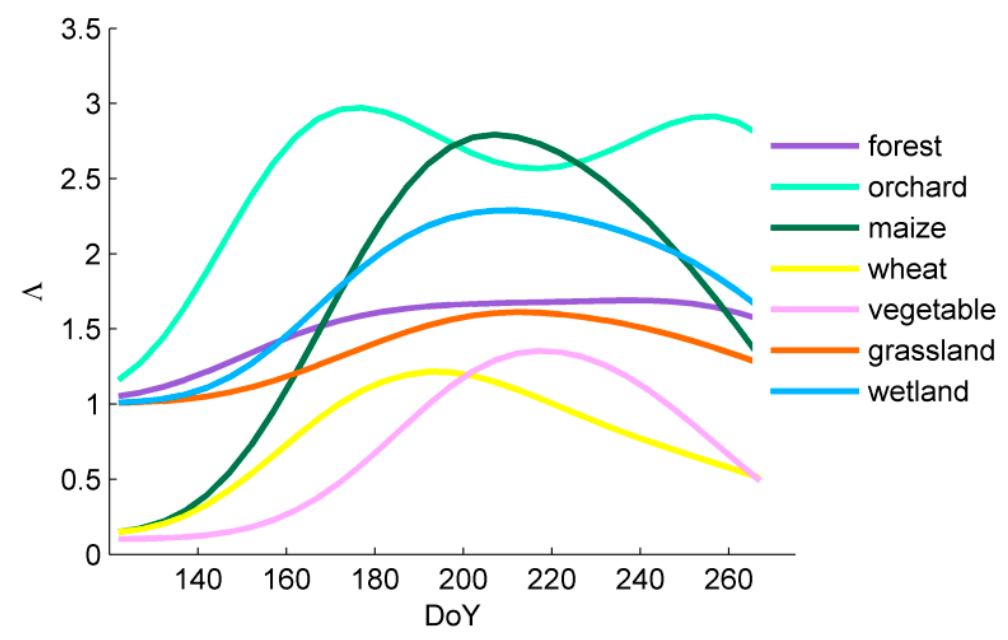

Figure 3. Time series of the area-averaged canopy area index $\Lambda(t)$ of different vegetation types during the growing season of 2012 in the middle reach of the Heihe River Basin.

The maps of vegetation height $h(t)$ for annual herbaceous plants were constructed by applying Equation (8) to the $L A I(t)$ maps. The empirical constants ( $e$ and $f$ ) in Equation (8) were obtained from the field canopy height and $L A I$ measurements as explained above (see Section 3.2.2). Table 6 gives the resulting $e$ and $f$ values, together with the R and RMSE. A summary of the LAI- $h$ results for annual herbaceous plants is shown in Table 6.

Table 6. The empirical parameters $e$ and $f$ in the $h(L A I)$ relationship (Equation (8)) for different vegetation types.

\begin{tabular}{cccc}
\hline Vegetable Type & $(\boldsymbol{e}, \boldsymbol{f})$ & $\mathbf{R}$ & RMSE \\
\hline $\begin{array}{c}\text { Maize } \\
\text { Wheat }\end{array}$ & $(0.95,-0.053)$ & 0.96 & 0.085 \\
\hline Vegetable & $(0.83,0.12)$ & 0.98 & 0.042 \\
\hline $\begin{array}{c}\text { Wetland } \\
\text { Grassland }\end{array}$ & $(0.58,0.54)$ & 1.0 & 0 \\
\hline
\end{tabular}

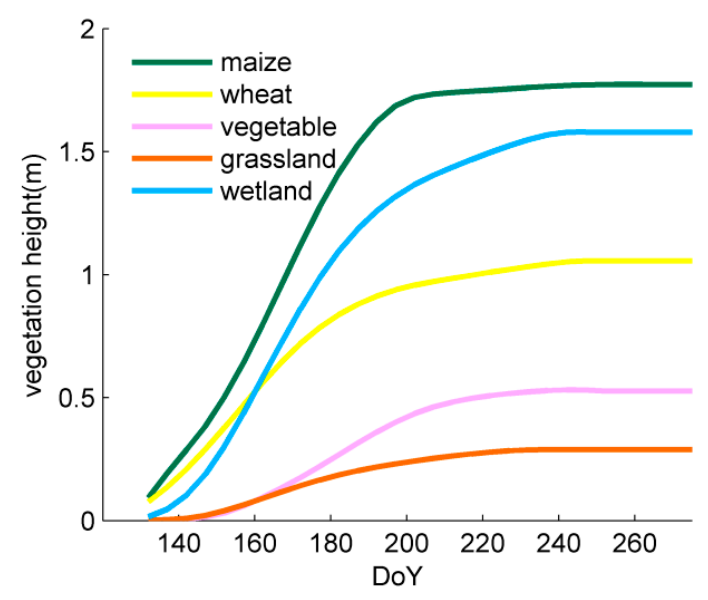

Figure 4. Time series of the area-averaged vegetation height of different herbaceous vegetation types during the growing season of 2012 in the middle reach of the Heihe River Basin. 
The maps of vegetation height $h(t)$ for the whole study area were derived from the $L A I(t)$ maps (estimated from HJ-1A/1B NDVI data) using the $e$ and $f$ values in Table 6 and the land cover map. The area-averaged vegetation height (Figure 4) of annual herbaceous plants increased over time as growing conditions became more favorable during the early growing season, and then stabilized in the mid growing season.

\subsection{Regional Scale Aerodynamic Roughness Length}

Maps of the aerodynamic roughness length $z_{0 \mathrm{~m}}(t)$ from May to September 2012 were constructed by applying Equation (1) using all canopy structure parameters derived from the HJ-1A/1B data and the model parameters described above. Figure 5 shows a time series of the area-averaged aerodynamic roughness length for different vegetation types from May to September of 2012. The magnitudes of the roughness length agree with values published for similar vegetation in the literature. Forest-type classes (orchard and forest) have much higher aerodynamic roughness lengths than non-forest type classes. The aerodynamic roughness lengths of the orchards and forests are about $0.46-0.5 \mathrm{~m}$ and $0.69-0.76 \mathrm{~m}$ (or approximately $0.09-0.1 \mathrm{~h}$ ), respectively. The range of the aerodynamic roughness lengths for the non-forest vegetation types is larger (Figure 5b), and the roughness lengths of maize and wetland showed the largest variability. This result is consistent with the canopy area index $\Lambda$ shown in Figure 3 . The grasslands displayed smaller aerodynamic roughness lengths and narrower ranges than the agricultural classes because of the relatively low vegetation height, the smaller variability of the roughness elements density and the absence of harvesting. The aerodynamic roughness length of grasslands and wetlands did not begin to decrease until September 2012, which is consistent with a longer growing season and a late season leaf loss.
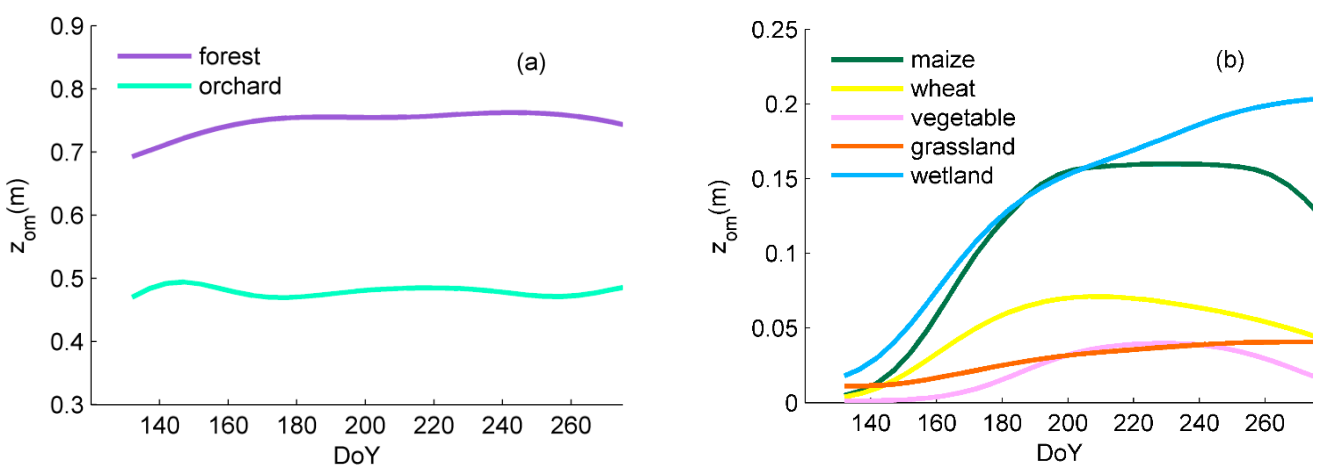

Figure 5. Time series of the regionally averaged aerodynamic roughness length during the growing season for different vegetation type: (a) forest vegetation; (b) non-forest vegetation.

Figures 6 and 7 illustrate the spatial distributions and histograms of the regional aerodynamic roughness length over the study area from May to September of 2012. To generate the histograms the roughness over the periods indicated (May-June, July-August and September, respectively) was averaged first. Next, the histogram over the entire region was calculated. The smallest spatial variability of the aerodynamic roughness lengths within class and among different classes occurred in May, when most crops were in the early stages of development. The greatest spatial differences among the different classes occurred in July and August, when most of the vegetable crops were in the booting stage. In Figures 6 and 7, the spatial variability among the different classes is also apparent in September because 
the canopy area index $\Lambda$ included the woody branches and dead leaves, which slows down the decrease in the density of the roughness elements and extends in time the apparent variability of the aerodynamic roughness length. The greatest variability occurred in June, mainly because the oasis is dominated by maize, and some deviations occurred in the sowing time. For the spring maize, June is the vegetative growth period and is characterized by the largest variability in vegetation height. In addition, the spatial variations of soil moisture, irrigation conditions, and soil fertility can contribute to the spatial variability in plant development, and the resulting spatial variability of the aerodynamic roughness length.

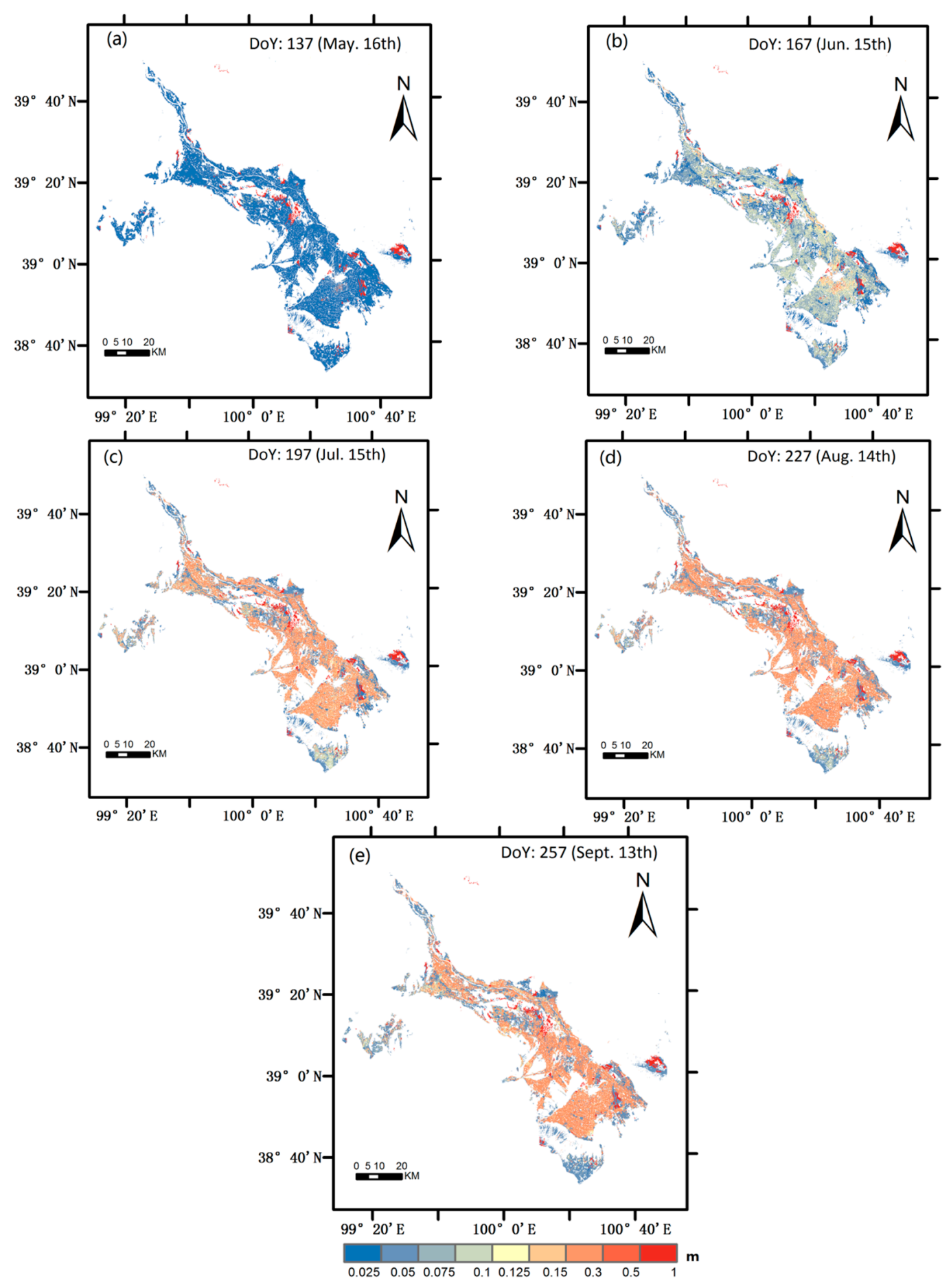

Figure 6. Aerodynamic roughness length in the period of May to September 2012 on days of year: (a) 137, (b) 167, (c) 197, (d) 227, and (e) 257. 

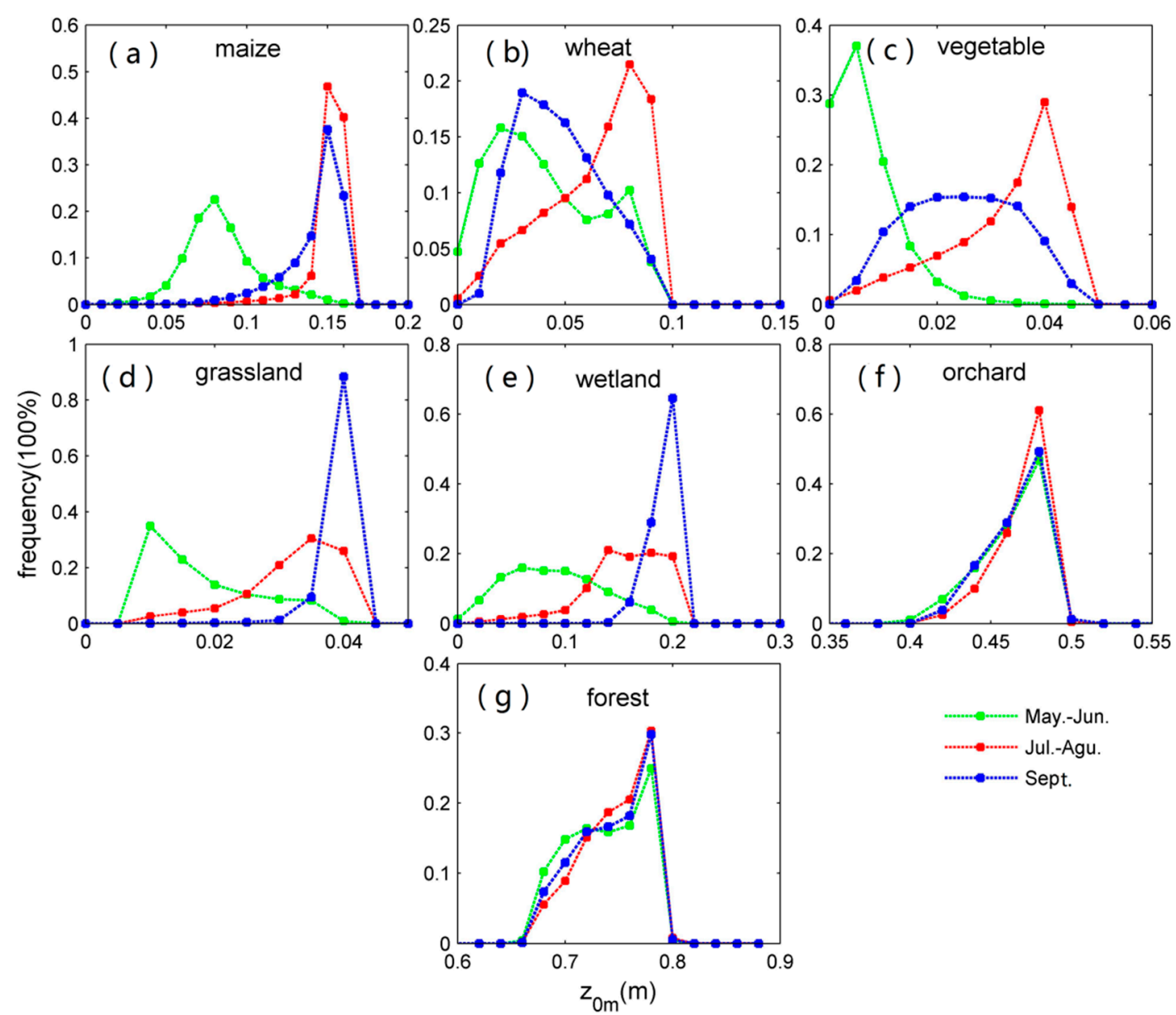

Figure 7. Histograms of $z 0 \mathrm{~m}$ in different growing seasons in 2012 (green curve: May-June; red curve: July-August; blue curve: September) for the different vegetation types over the study area (middle reach of Heihe River Basin): (a) maize; (b) wheat; (c) vegetable; (d) grassland; (e) wetland; (f) orchard and (g) forest.

\subsection{Validation and Comparison of the Aerodynamic Roughness Length Results}

The aerodynamic roughness length estimated at the flux tower sites by the profile method (see Section 3.3) was used to validate the remote sensing model results for each site (see Figure 8). The error bars indicate the confidence intervals of the data, and the diameter of the circle in the middle of each error bar indicates the number of degrees of freedom for each robust regression (equivalent to the number of observations). Figure 8 shows that the greater the degrees of freedom the shorter are the error bars, which is to be expected. The coefficient of correlation, $\mathrm{R}$ and the RMSE are used to evaluate the results. Overall, the R92 method with the revised parameter sets of Jasinski et al. (2005) [20] provided seasonal trends and magnitudes that were similar to the EC derived aerodynamic roughness length, except for the orchard (Figure 81). For the orchard (Figure 81), the correlation between the remote sensing model estimates and the ground measured roughness length was rather poor. Compared with the other vegetation classes, the remote sensing (RS) results for the orchard class show less variability, this is partly due to the fact that the period of ground measurement in the orchard site was too short to capture the full growth of the fruit trees. In this case, longer time series of ground measurements should be added for further comparison. For wetlands, the model performs well, with relatively high R-values and low RMSE values. For maize, 
more sites are available for validation, and the RS roughness length model performed differently among different sites when compared with the measurements. Most of the sites showed high correlation, although the aerodynamic roughness length is usually underestimated by the remote sensing model.
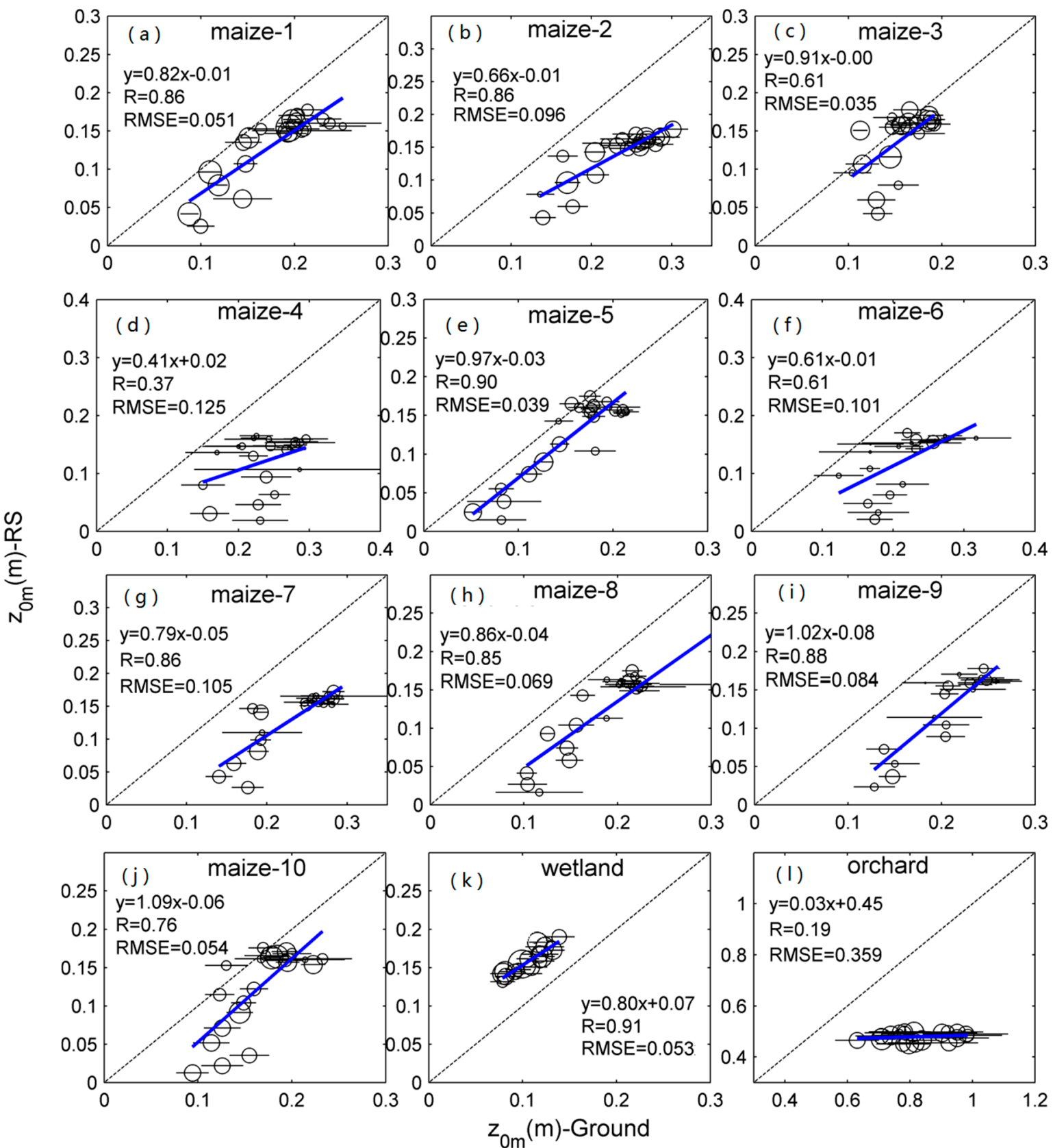

Figure 8. Comparison between the estimated aerodynamic roughness length and the ground measurements from EC experimental sites $(\mathbf{a}-\mathbf{l})$ in the middle reach of the Heihe River Basin in 2012. Each circle is the area-Averaged value over five days. The diameters of the circle scale with the number of degrees of freedom (equivalent to the number of observations) for each robust regression. The error bars indicate the $95 \%$ confidence intervals of the regression estimate.

\section{Discussion}

Although Jasinski et al. (2005) [20] used a broader range of canopy density and land cover types for parameters estimation, the parameters used in this model are still locally limited. The four vegetation types 
used by Jasinski et al. (2005) [20] may be insufficient to capture the geometric features of all vegetation types and finer model tuning may be needed (using ground measurements) for different vegetation classes.

Multi-spectral image data cannot replace local and direct measurements of aerodynamic roughness length. However, compared with ground measurements, remote sensing data have the advantages of wider coverage, relatively inexpensive and are easily obtained. Fine temporal and spatial resolution image data will be available as multiple satellites will provide similar measurements. This will make regional monitoring of aerodynamic roughness length easier, especially in heterogeneous areas. In this sense, deriving the land surface roughness length data using remote sensing observations is valuable.

The aerodynamic roughness length parameterizes momentum absorption, which can be affected by surrounding pixels, and the parameterization is non-linear. The aerodynamic roughness length is inherently related to the height over the surface of momentum flux measurements and their footprint. Different applications may require $z 0 \mathrm{~m}$ maps at different spatial resolutions. Strictly speaking, the aerodynamic roughness length is meaningful only over on homogeneous surfaces and within the surface layer in dynamic equilibrium with the underlying surface. Thus, the mixed pixels of coarse resolution multi-spectral image data will result in large error of estimate on both aerodynamic roughness length and turbulent fluxes. Thus, this study investigated the aerodynamic roughness length at fine spatial (30 m) and temporal (5 day) resolutions which is meaningful for regional scale modelers. Maps of aerodynamic roughness length at very high resolution are not really consistent with the physics underlying the logarithmic parameterization of $u(z)$ and momentum flux. In addition, with the development of high resolution earth system models, which resolve increasingly finer scales of atmosphere dynamics, more knowledge of the relationships between the vegetation geometry and the model parameters relevant to a specific scale should be included [45].

As illustrated in Figure 8, deviations exist between EC estimations and model results, as well as among different vegetation classes. These deviations could occur for the following reasons: (1) Errors could exist in the EC measurements. Although the EC technique is usually the most accurate method for estimating aerodynamic roughness length, errors still exist when measurement conditions do not completely satisfy the basic assumptions, e.g., flat wind field, Taylor hypothesis, fast enough sampling rate, and enough averaging time for large scale eddies [46]. (2) The aerodynamic roughness itself is not only related to the geometry of the vegetation but also affected by meteorological conditions, such as the velocity and direction of the wind and the atmospheric stability. Different wind directions result in different measurement footprints i.e., deviations will appear in the aerodynamic roughness length when the land surface is heterogeneous. Figure $9 \mathrm{a}$ shows that the distribution of the $z 0 \mathrm{~m}$ values estimated from the EC measurements of maize (site 1) changes with wind direction. For site 1, three lines of windbreak trees south of the site result in a large value of $z 0 \mathrm{~m}$ for that wind direction (see Figure $9 \mathrm{a}$ ). Furthermore, because vegetation is not a rigid body, its geometry can change with wind speed. Figure $9 \mathrm{~b}$ implies that this effect occurs, where $z 0 \mathrm{~m}$ values decreased with increasing wind speed. Atmospheric stability provides an indication of thermal turbulence to some extent, and can also affect the EC measurements. (3) Topography may also result in a relatively large $z 0 \mathrm{~m}$; however, this effect is negligible given the very flat topography of our study area. 

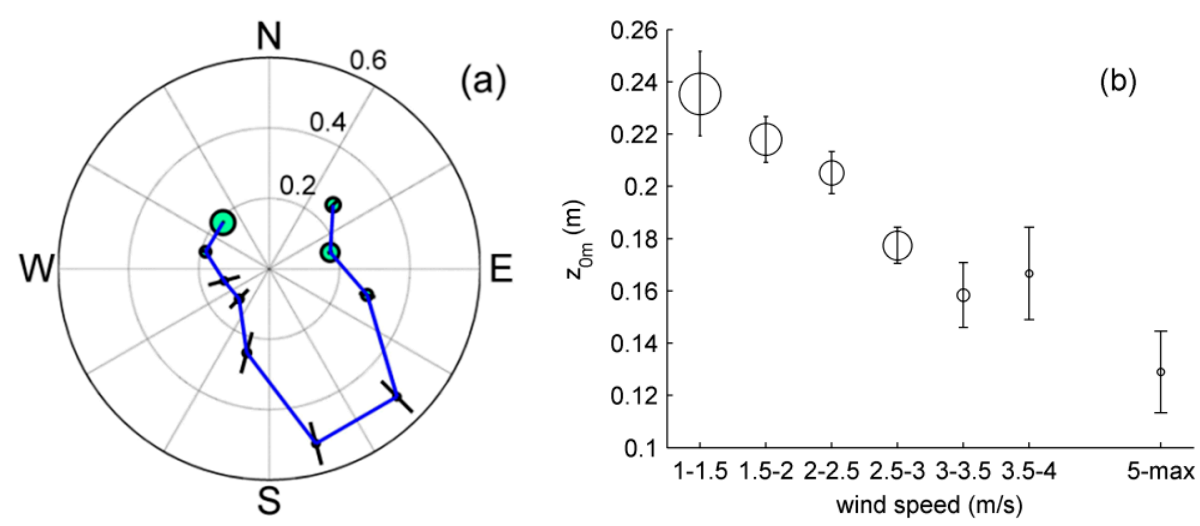

Figure 9. Examples of aerodynamic roughness length changing with atmospheric conditions: (a) variation of EC-derived roughness with wind direction for maize site 1, indicating suboptimal fetch conditions in the south; (b) EC-derived roughness against wind speed for maize site 1 , indicating the effect of crop bending with increased wind on the roughness length. The size of the circles in both (a) and (b) scales by the degrees of freedom in each fitting program, and error bars centered at each data point indicate $95 \%$ confidence intervals of the regression estimate.

\section{Conclusions}

The current research presents a practical approach for generating regional vegetation aerodynamic roughness lengths with fine temporal and spatial resolutions by combining remote sensing and ground measurements. In this study, the basic framework of the Raupach (1992) [18] (R92) model and the new parameters revised by Jasinsiki et al. (2005) [20] were adapted to derive the ratio of height-normalized aerodynamic roughness length to vegetation height, $z 0 \mathrm{~m} / h$. The multi-spectral image data acquired by the HJ-1A/1B satellites were used to construct a land cover map based on a supervised classification method, fine resolution $L A I$ maps and vegetation height maps using the empirical methods proposed in this paper, which performed well in our study area. Eventually, the aerodynamic roughness length, which is preferred by users, is generated rather than the ratio $z 0 \mathrm{~m} / h$. The values and seasonal variations of aerodynamic roughness lengths for different vegetation types were different. Trees (orchard and forest) have much higher aerodynamic roughness lengths and less variability than the non-forest type classes.

Taking the advantage of the dense field EC tower measurements in the middle reach of the Heihe River Basin, the aerodynamic roughness length product was evaluated over different vegetation types. Aerodynamic roughness data from the EC tower sites were used as reference data and directly compared with the results derived from the remote sensing method using satellite data. Overall, the model performed well at wetland and maize sites but not at the orchard site. This discrepancy possibly occurred for several reasons, such as errors from EC ground measurements, and the accuracy of the model. The difference in the footprints between the ground measurements and remote sensing observations, combined with suboptimal fetch conditions from some of the former, may also explain some of this disagreement. Nevertheless, we are confident that implementing the R92 framework, enhanced by explicit vegetation height estimates, will provide improved distributed roughness length estimates for a range of applications. 


\section{Acknowledgments}

This work is jointly supported by the National Key Basic Research Program of China (Grant No. 2015CB953702), the National Natural Science Foundation of China (NSFC) (Grant No. 91425303) and the project of CAS Visiting Professorships for Senior International Scientists.

\section{Author Contributions}

Qiting Chen mainly wrote the manuscript and was responsible for the research design, data preparation and analysis. Li Jia supervised the research including methodology development, as well as manuscript structure, writing and revision. Ronald Hutjes contributed to the validation approach and manuscript editing and revision. Massimo Menenti provided manuscript editing and revision.

\section{Conflicts of Interest}

The authors declare no conflict of interest.

\section{References}

1. Toda, M.; Sugita, M. Single level turbulence measurements to determine roughness parameters of complex terrain. J. Geophys. Res. 2003, 108, doi:10.1029/2002JD002573.

2. Brutsaert, W. Evaporation into the Atmosphere: Theory, History, and Applications; Springer: New York, NY, USA, 1982.

3. Stull, R.B. An Introduction to Boundary Layer Meteorology; Springer: New York, NY, USA, 1988; Volume 13.

4. Martano, P. Estimation of surface roughness length and displacement height from single-level sonic anemometer data. J. Appl. Meteorol. 2000, 39, 708-715.

5. Garratt, J. The internal boundary layer-A review. Bound. Layer Meteorol. 1990, 50, 171-203.

6. Maurer, K.D.; Hardiman, B.S.; Vogel, C.S.; Bohrer, G. Canopy-structure effects on surface roughness parameters: Observations in a Great Lakes mixed-deciduous forest. Agric. For. Meteorol. 2013, 177, 24-34.

7. Colin, J.; Faivre, R. Aerodynamic roughness length estimation from very high-resolution imaging LiDAR observations over the Heihe basin in China. Hydrol. Earth Syst. Sci. 2010, 14, 2661-2669.

8. Hasager, C.; Jensen, N. Surface-flux aggregation in heterogeneous terrain. Q. J. R. Meteorol. Soc. 1999, 125, 2075-2102.

9. Menenti, M.; Ritchie, J.; Humes, K.; Parry, R.; Pachepsky, Y.; Gimenez, D.; Leguizamon, S. Estimation of aerodynamic roughness at various spatial scales. In Scaling up in Hydrology Using Remote Sensing; John Wiley and Sons: Chichester, UK, 1996; Volume 272.

10. Menenti, M.; Ritchie, J.C. Estimation of effective aerodynamic roughness of Walnut Gulch watershed with laser altimeter measurements. Water Resour. Res. 1994, 30, 1329-1337.

11. De Vries, A.; Kustas, W.; Ritchie, J.; Klaassen, W.; Menenti, M.; Rango, A.; Prueger, J. Effective aerodynamic roughness estimated from airborne laser altimeter measurements of surface features. Int. J. Remote Sens. 2003, 24, 1545-1558. 
12. Sarwar, A.; Bill, R. Mapping evapotranspiration in the Indus Basin using ASTER data. Int. J. Remote Sens. 2007, 28, 5037-5046.

13. Jia, L.; Wang, J.M.; Menenti, M. Estimation of area roughness length for momentum using remote sensing data and measurements in field. Sci. Atmos. Sin. 1999, 23, 632-640.

14. Lettau, H. Note on aerodynamic roughness-parameter estimation on the basis of roughness-element description. J. Appl. Meteorol. 1969, 8, 828-832.

15. MacDonald, R.W.; Griffiths, R.F.; Hall, D.J. An improved method for the estimation of surface roughness of obstacle arrays. Atmos. Environ. 1998, 32, 1857-1864.

16. Choudhury, B.; Monteith, J. A four-layer model for the heat budget of homogeneous land surfaces. Q. J. R. Meteorol. Soc. 1988, 114, 373-398.

17. Shaw, R.H.; Pereira, A. Aerodynamic roughness of a plant canopy: A numerical experiment. Agric. Meteorol. 1982, 26, 51-65.

18. Raupach, M.R. Drag and drag partition on rough surfaces. Bound. Layer Meteorol. 1992, 60, 375-395.

19. Raupach, M. Simplified expressions for vegetation roughness length and zero-plane displacement as functions of canopy height and area index. Bound. Layer Meteorol. 1994, 71, 211-216.

20. Jasinski, M.F.; Borak, J.; Crago, R. Bulk surface momentum parameters for satellite-derived vegetation fields. Agric. For. Meteorol. 2005, 133, 55-68.

21. Borak, J.S.; Jasinski, M.F.; Crago, R.D. Time series vegetation aerodynamic roughness fields estimated from MODIS observations. Agric. For. Meteorol. 2005, 135, 252-268.

22. Zhou, Y.; Ju, W.; Sun, X.; Wen, X.; Guan, D. Significant decrease of uncertainties in sensible heat flux simulation using temporally variable aerodynamic roughness in two typical forest ecosystems of China. J. Appl. Meteorol. Climatol. 2012, 51, 1099-1110.

23. Zhang, J.-H.; Li, G.-D.; Nan, Z.-R.; Xiao, H.-L.; Zhao, Z.-S. The spatial distribution of soil organic carbon storage and change under different land uses in the middle of Heihe River. Sci. Geogr. Sin. 2011, 31, 982-988.

24. Wang, J.; Hu, Y.; Sahashi, K.; Mitsuta, Y. Outline of HEIFE field observations. In Proceedings of the International Symposium on Heife, Kyoto, Japan, 8-11 November 1993; pp. 22-29.

25. Li, X.; Li, X.; Li, Z.; Ma, M.; Wang, J.; Xiao, Q.; Liu, Q.; Che, T.; Chen, E.; Yan, G. Watershed allied telemetry experimental research. J. Geophys. Res. 2009, 114, doi:10.1029/2008JD011590.

26. Li, X.; Cheng, G.; Liu, S.; Xiao, Q.; Ma, M.; Jin, R.; Che, T.; Liu, Q.; Wang, W.; Qi, Y. Heihe watershed allied telemetry experimental research (HiWATER): Scientific objectives and experimental design. Bull. Am. Meteorol. Soc. 2013, 94, 1145-1160.

27. Xu, Z.; Liu, S.; Li, X.; Shi, S.; Wang, J.; Zhu, Z.; Xu, T.; Wang, W.; Ma, M. Intercomparison of surface energy flux measurement systems used during the Hiwater-Musoexe. J. Geophys. Res. 2013, 118, 13140-113157.

28. Liu, S.; Xu, Z.; Wang, W.; Jia, Z.; Zhu, M.; Bai, J.; Wang, J. A comparison of eddy-covariance and large aperture scintillometer measurements with respect to the energy balance closure problem. Hydrol. Earth Syst. Sci. 2011, 15, 1291-1306.

29. Hiwater Project Data. Available online: http://westdc.westgis.ac.cn (accessed on 20 November 2014).

30. HJ-1A/1B Satellite Data. Available online: http://218.247.138.121/DSSPlatform/index.html (accessed on 20 November 2014).

31. Thom, A. Momentum absorption by vegetation. Q. J. R. Meteorol. Soc. 1971, 97, 414-428. 
32. Zeng, X.B.; Shaikh, M.; Dai, Y.J.; Dickinson, R.E.; Myneni, R. Coupling of the common land model to the NCAR community climate model. J. Clim. 2002, 15, 1832-1854.

33. Jordan, C.F. Derivation of leaf-area index from quality of light on the forest floor. Ecology 1969, 50, 663-666.

34. Baret, F.; Guyot, G. Potentials and limits of vegetation indices for LAI and APAR assessment. Remote Sens. Environ. 1991, 35, 161-173.

35. Chen, J.M.; Cihlar, J. Retrieving leaf area index of boreal conifer forests using Landsat TM images. Remote Sens. Environ. 1996, 55, 153-162.

36. Verhoef, W.; Menenti, M.; Azzali, S. Cover a colour composite of NOAA-AVHRR-NDVI based on time series analysis (1981-1992). Int. J. Remote Sens. 1996, 17, 231-235.

37. Menenti, M.; Azzali, S.; Verhoef, W.; van Swol, R. Mapping agroecological zones and time lag in vegetation growth by means of Fourier analysis of time series of NDVI images. Adv. Sp. Res. 1993, 13, 233-237.

38. Jia, L.; Shang, H.; Hu, G.; Menenti, M. Phenological response of vegetation to upstream river flow in the Heihe River basin by time series analysis of MODIS data. Hydrol. Earth Syst. Sci. 2011, 15, 1047-1064.

39. Harding, D.J.; Carabajal, C.C. ICESat waveform measurements of within-footprint topographic relief and vegetation vertical structure. Geophys. Res. Lett. 2005, 32, doi:10.1029/2005GL023471.

40. Flood, M. LiDAR activities and research priorities in the commercial sector. Int. Arch. Photogramm. Remote Sens. Spat. Inf. Sci. 2001, 34, 3-8.

41. Liu, X. Airborne LiDAR for DEM generation: Some critical issues. Prog. Phys. Geogr. 2008, 32, 31-49.

42. Lim, K.; Treitz, P.; Wulder, M.; St-Onge, B.; Flood, M. LIDAR remote sensing of forest structure. Prog. Phys. Geogr. 2003, 27, 88-106.

43. Gao, S.; Niu, Z.; Huang, N.; Hou, X. Estimating the Leaf Area Index, height and biomass of maize using HJ-1 and RADARSAT-2. Int. J. Appl. Earth Obs. Geoinf. 2013, 24, 1-8.

44. Chen, J.Y.; Wang, J.M.; Mitsuaki, H. An independent method to determine the surface roughness length. Chin. J. Atmos. Sci. 1993, 17, 21-26.

45. Beven, K.J.; Cloke, H.L. Comment on "Hyperresolution global land surface modeling: Meeting a grand challenge for monitoring Earth's terrestrial water" by Eric F. Wood et al. Water Resour. Res. 2012, 48, doi:10.1029/2011WR010982.

46. Aubinet, M.; Vesala, T.; Papale, D. Eddy Covariance: A Practical Guide to Measurement and Data Analysis; Springer: New York, NY, USA, 2012.

(C) 2015 by the authors; licensee MDPI, Basel, Switzerland. This article is an open access article distributed under the terms and conditions of the Creative Commons Attribution license (http://creativecommons.org/licenses/by/4.0/). 